\title{
Racine et l'Histoire, textes réunis et publiés par MARIE-CLAUDE CANOVA GREEN et ALAIN VIALA
}

\section{Monica Pavesio}

\section{OpenEdition}

\section{Journals}

\section{Edizione digitale}

URL: http://journals.openedition.org/studifrancesi/33117

DOI: 10.4000/studifrancesi.33117

ISSN: 2427-5856

\section{Editore}

Rosenberg \& Sellier

\section{Edizione cartacea}

Data di pubblicazione: 1 décembre 2005

Paginazione: 635

ISSN: 0039-2944

\section{Notizia bibliografica digitale}

Monica Pavesio, «Racine et l'Histoire, textes réunis et publiés par mARIE-CLAUDE CANOVA GREEN Et ALAIN VIALA», Studi Francesi [Online], 147 (XLX | III) | 2005, online dal 01 novembre 2015, consultato il 18 avril 2021. URL: http://journals.openedition.org/studifrancesi/33117; DOI: https://doi.org/10.4000/studifrancesi. 33117

Questo documento è stato generato automaticamente il 18 avril 2021.

\section{(c) (i) (9)}

Studi Francesi è distribuita con Licenza Creative Commons Attribuzione - Non commerciale - Non opere derivate 4.0 Internazionale. 


\title{
Racine et l'Histoire, textes réunis et publiés par MARIE-CLAUDE CANOVA GREEN et ALAIN VIALA
}

\author{
Monica Pavesio
}

\section{NOTIZIA}

Racine et l'Histoire, textes réunis et publiés par MARIE-CLAUDE CANOVA GREEN et ALAIN VIALA, Biblio 17-155, Tübingen, Gunter Narr Verlag, 2004, pp. 267.

1 Il volume riunisce i quattordici contributi presentati al convegno organizzato a Londra nel maggio del 1999 da Marie-Claude Canova Green e Alain Viala, in occasione del tricentenario della morte di Racine.

2 Il soggetto, sul quale sono stati chiamati a confrontarsi alcuni tra i più importanti studiosi di Racine, è il rapporto del drammaturgo con la Storia. A lungo si è creduto infatti che l'accesso di Racine nel 1677 al ruolo di storiografo di Luigi XIV sia stato una specie di incidente di percorso nel suo itinerario poetico e drammatico. I due curatori ricordano invece nell'introduzione al volume, che nel Seicento occuparsi di Storia non significava uscire dall'ambito della letteratura e che la scissione fra poesia drammatica e Storia non è che una pura illusione ottica nelle opere del grande drammaturgo.

3 I contributi presenti cercano di mettere in evidenza l'ambiguo rapporto che Racine intrattenne con la Storia, ambiguità che emerse in tutta la sua interezza quando fu chiamato al ruolo di storiografo di un re assolutista ed accentratore. Un mestiere difficile, il cui statuto era incerto e continuamente soggetto a variazioni da parte della monarchia, che Racine portò avanti con rigore, anche se con alcune perplessità.

4 Tre sezioni compongono il volume: la prima (Théâtre racinien et lectures de l'histoire) indaga i legami del teatro raciniano sacro e profano con la Storia e le modalità con le quali il drammaturgo ha utilizzato la storia religiosa e profana nelle sue opere. 
Ricordiamo in questa sezione i lavori di Ch. Delmas sulla mitizzazione della Storia nella tragedia classica e raciniana (Histoire et Mythe, pp. 57-68) e di F. Sick sulla sostituzione da parte di Racine del tragico storico corneliano con una differente concezione della Storia che subordina l'ordine degli avvenimenti alle passioni (Une Poétique de la ruse: l'Histoire dans les tragédies de Racine, pp. 69-82).

5 La seconda sezione (Racine et l'écriture de l'Histoire) presenta due contributi di carattere generale che illustrano il mestiere di storiografo ai tempi dell'assolutismo monarchico e la stesura della Storia al servizio della monarchia, e quattro studi sul lavoro di Racine come storiografo reale ed, in particolare, sul suo Abrégé de l'Histoire de Port-Royal, testo in cui il drammaturgo diventato storico si interroga sulla scrittura encomiastica del potere e sul suo stesso ruolo di storico al servizio del potere. 